\title{
Immunotherapy for fungal infections with special emphasis on central nervous system infections
}

\author{
lyer G. Parameswaran, Brahm H. Segal* \\ Division of Infectious Diseases, University at Buffalo School of Medicine and Biomedical Sciences, Buffalo, NY; *Division of Infectious \\ Diseases, Roswell Park Cancer Institute, Elm and Carlton Streets, Buffalo, NY, 14263 USA
}

\begin{abstract}
Opportunistic fungal infections are major causes of morbidity and mortality in the immunocompromized. Fungi have evolved complex and coordinated mechanisms to survive in the environment and the mammalian host. Fungi must adapt to "stressors" in the host, including nutrient scarcity, $\mathrm{pH}$ and reactive oxygen and nitrogen intermediates, in addition to evading host immunity. Knowledge of the immunopathogenesis of fungal infections has paved the way to promising strategies for immunotherapy. These include strategies that increase phagocyte number, activate innate host defense pathways in phagocytes and dendritic cells and stimulate antigenspecific immunity (e.g., vaccines). Immunotherapy must be tailored to specific immunocompromized states. Our review focuses on cryptococcosis and coccidioidomycosis because of the propensity of these diseases to involve the central nervous system (CNS). The CNS has long been considered "immunologically privileged" in the sense of being isolated from normal immune surveillance. This notion is only partially accurate. Immune-based therapies for fungal CNS disease are at an exploratory level and merit further evaluation in clinical trials.
\end{abstract}

Key words: Aspergillosis, central nervous system fungal infections, cryptococcosis, immunotherapy, opportunistic infections

Opportunistic fungal infections are a major cause of morbidity and mortality in immunocompromized patients. The major defects in host defense that render susceptibility to opportunistic fungal infections are summarized in Table 1. Deficits in host defense which render persons susceptible to fungal infections are complex, but can be broadly divided into the following categories: 1) neutropenia; 2) qualitative deficits in phagocyte function; 3) deficits in cell-mediated immunity; 4) deficits in humoral immunity; and 5) deficits in mucosal immunity.

Patients often have multiple defects in immunity predisposing to opportunistic fungal infections. There is now significant interest in several immunomodulatory strategies to combat opportunistic fungal infections, which of course need to be tailored to specific immunocompromised populations. These strategies broadly include colony growth factors, granulocyte transfusions (in neutropenic patients), recombinant cytokines, passive immunization with monoclonal antibodies and vaccine development [Table 2].

Opportunistic yeasts produce a spectrum of clinical disease that ranges from superficial and mucosal infections to disseminated disease. Candida species are endogenous flora that may gain access to the bloodstream through breeches in anatomical barriers. Oral mucosal candidiasis usually reflects severe T-cell depression commonly associated with AIDS or highdose systemic corticosteroids. The bowel is the principal portal of entry in patients with acute leukemia receiving mucotoxic regimens. ${ }^{[1]}$

Host defense against Cryptococcus neoformans is also principally dependent on T-cell immunity. Thus, patients with AIDS, stem cell and solid organ transplant recipients and other patients receiving intensive immunosuppressive therapy are at risk for cryptococcal disease. Immunoglobulins directed against capsular epitopes and complement facilitate phagocytosis of the organism and play a role in host defense. ${ }^{[2-6]}$ The principal portal of entry for C. neoformans is by inhalation, with subsequent spread to the blood and central nervous system.

Endemic dimorphic include Histoplasma capsulatum, Coccidioides immitis, Blastomyces dermatitidis, Paracoccidioides brasiliensis, Sporothrix schenkii and Penicillium marneffei. Dimorphic fungi cause infections in immunocompetent persons, but severe infections with dissemination are more common in patients with compromised cellular immunity (e.g., AIDS, transplant recipients).

Filamentous fungi (moulds) are ubiquitous soil 
Table 1: Immunodeficiencies predisposing to opportunistic fungal infections

\section{Immunodeficiency or patient group}

Neutropenia

Qualitative neutrophil dysfunction (inherited)

Mucosal immunity deficit

Defective cellular immunity

Allogeneic hematopoietic stem cell transplant recipients, by time after transplantation

$<1$ month

1-6 months

\section{Population(s) at highest risk}

Patients receiving cytotoxic chemotherapy for malignancy, conditioning regimen for hematopoietic stem cell transplantation or radiation therapy; patients with aplastic anemia Patients with chronic granulomatous disease

Patients receiving mucotoxic chemotherapy (e.g., anthracycline regimens for acute leukemia); patients with graft-versus-host disease of the gastrointestinal tract Patients with AIDS or with certain leukemias and lymphomas; patients receiving corticosteroids, calcineurin inhibitors, anti-lymphocyte immunoglobulin preparations, anti-TNF- $\alpha$ agents (e.g., infliximab), purine analogues (e.g., fludarabine) and alemtuzumab

Patients with neutropenia and mucosal damage from conditioning regimen Patients with cellular and humoral immunodeficiency; patients receiving high-dose steroids for graft-versus-host disease, which causes global immunosuppression and disables phagocyte and cellular immunity Patients with graft-versus-host disease; patients receiving a transplant from an HLA haplotype-mismatched or unrelated donor; patients with a T-cell-depleted allograft, lymphopenia or cytomegalovirus disease; patients with multiple stem cell transplantations ${ }^{\text {a }}$

\section{Fungal pathogen(s)}

Aspergillus species and other filamentous fungi (e.g, zygomycetes, Fusarium and Scedosporium species), Candida species, Trichosporon species

Aspergillus species and other filamentous fungi

Candida species

Aspergillus species and other filamentous fungi, Candida species, Cryptococcus neoformans, dimorphic fungi, Pneumocystis jirovecii (formerly Pneumocystis carinii)

Aspergillus species and other filamentous fungi, Candida species Aspergillus species and other filamentous fungi, Candida species, $C$. neoformans, dimorphic fungi, $P$. jirovecii

Aspergillus species and other filamentous fungi, Candida species, $C$. neoformans, dimorphic fungi, $P$. jirovecii

Table 2: Goals and strategies for augmentation of the immune response to fungal infections

an allogeneic hematopoietic stem cell transplant recipients, partial reconstitution of cellular immunity is expected and the risk of opportunistic fungal infections is reduced at $\geq 6$ months after transplantation in the absence of graft-versus-host disease. However, graft-versus-host disease requiring intensive immunosuppressive therapy (e.g., corticosteroids) disables neutrophil and macrophage function and prevents reconstitution of cellular and humoral immunity. Such patients are at high risk for invasive fungal infection late after transplantation.

Note: This table is adapted from Table 1 in Segal et al. Immunotherapy for Fungal Infections, Clin Infect Dis, 2006; 42:507-15

\begin{tabular}{ll}
\hline Goal & Strategies \\
Increase in neutrophil number & CSFs (G-CSF and GM-CSF); granulocyte transfusions; myeloid \\
& progenitors (common myeloid progenitors, granulocyte-monocyte \\
progenitors); thymosin- 1 1 & CSFs (G-CSF and GM-CSF); cytokines (e.g, recombinant IFN- $\gamma$ ); \\
chemokines; TLR activation & \\
Activation of neutrophils & Colony-stimulating factors (macrophage colony-stimulating factor and \\
Activation of macrophages and dendritic cells & GM-CSF); cytokines (e.g, recombinant IFN- $\gamma$ ); TLR activation \\
& Cytokines (e.g, recombinant IFN- $\gamma$ ); TLR activation; pentraxin 3; \\
theightened cellular immunity & $\begin{array}{l}\text { Vaccines; antibody administration (e.g., monoclonal antibody 18B7 } \\
\text { for Cryptococcus neoformans) }\end{array}$
\end{tabular}

Most of the listed strategies are experimental and have not been evaluated among patients. G-CSF, granulocyte CSF; GM-CSF, granulocyte-macrophage CSF; TLR, toll-like receptor.

Note: This table is adapted from Table 2 in Segal et al. Immunotherapy for Fungal Infections, Clin Infect Dis, 2006; 42:507-15

inhabitants whose conidia (spores) we inhale on a regular basis. The sinopulmonary tract is the most common portal of entry. The respiratory mucosa and alveolar macrophages constitute the first line of host defense against conidia. At the hyphal stage, neutrophils are most important in controlling infection.
The frequency of mortality from invasive aspergillosis has increased by several-fold over the past 10 to 20 years. ${ }^{[7,8]}$ Patients at risk include those with neutropenia and leukemia, allogeneic hematopoietic stem cell transplant (HSCT) recipients, solid organ transplant recipients (particularly lung), chronic granulomatous 
disease (CGD) and advanced AIDS. ${ }^{[8-10]}$ Among allogeneic HSCT recipients, factors that increase the risk of invasive mould infections after neutrophil recovery include graft-versus-host disease (GVHD), human leukocyte antigen haplotype-mismatched or unrelated donors, receipt of T-cell depleted allografts, lymphopenia, receipt of systemic corticosteroids and cytomegalovirus disease. ${ }^{[11-15]}$ Non-Aspergillus moulds including Fusarium species and zygomycetes have been observed with greater frequency among patients undergoing multiple stem cell transplants, a reflection of severe immunocompromise. ${ }^{[16]}$

\section{Central Nervous System Fungal Infections}

Any fungal infection can theoretically cause central nervous system (CNS) disease via hematogenous dissemination. C. neoformans, for reasons that are not well understood, has a tropism for the CNS. This yeast is ubiquitous in the environment and acquisition of infection is via inhalation. If the infection is not contained, hematogenous infection with distant seeding may occur. Meningitis is the most common manifestation of cryptococcal disease.

Dimorphic fungi can also cause CNS disease via inhalation and hematogenous dissemination. Of the dimorphic fungi, CNS disease is probably the most common in coccidioidomycosis. CNS coccidioidomycosis is not reliably eradicated even with prolonged antifungal therapy, necessitating the need for life-long treatment. ${ }^{[17]}$

Vaccine development is a priority for several fungal pathogens, including Candida spp., C. neoformans, Aspergillus spp., and the dimorphic fungi, H. capsulatum, C. immitis and $B$. dermatiditis. ${ }^{[18-21]}$ This requires knowledge about host-pathogen interactions and mechanisms that the pathogen has evolved to evade host defense and survive in a hostile environment. Knowledge about specific mechanisms (virulence factors) that the pathogen uses to colonize, invade and proliferate in the host sheds light on potential targets for drug development and immunotherapy.

CNS disease is an uncommon complication of candidemia. Central nervous system disease complicating invasive aspergillosis and other mould infections can occur via direct extension from sino-orbital disease or via hematogenous dissemination. CNS mould infections are often rapidly fatal and will likely not be amenable to immunotherapy once CNS disease has occurred..$^{[22,23]}$ For these reasons, our review will focus on immunotherapeutic strategies targeted to CNS cryptococcosis and coccidioidomycosis.

The CNS has long been considered "immunologically privileged" in the sense of being isolated from normal immune surveillance. This notion is only partially accurate. Clearly, bacterial meningitis is associated with a robust cerebrospinal fluid (CSF) neutrophilic leukocytosis. Viral meningoencephalitides and chronic meningitis related to mycobacterial and fungal infections induce a variable CSF leukocytic pleocytosis. The brain is also a site where antigen display through major histocompatibility complexes can occur. Sensitized T-cells to myelin protein constituents are able to cross the blood-brain barrier and mediate multiple sclerosis in patients and experimental autoimmune encephalomyelitis. ${ }^{[2]}$ This has raised interest in whether immunological manipulation can be used therapeutically when targeted against CNS tumors and infectious diseases. As we discuss, immunomodulatory strategies targeted to CNS fungal diseases are at an exploratory level.

\section{Immunomodulatory Strategies}

Immunomodulatory strategies can be applied in two different modes: prevention and therapy of established disease. In the prevention mode, a specific patient population at risk for an invasive fungal infection received an immunomodulator, such as a vaccine. Since cryptococcal disease occurs principally in persons with severe T-cell impairment (e.g., AIDS), an efficacy trial evaluating a hypothetical cryptococcal vaccine would focus on specific high-risk patients.

In contrast, the risk for coccidioidomycosis is principally geographic. Coccidioidomycosis is endemic in the southwestern United States and, thus, a prevention strategy against coccidioidomycosis would focus on persons living in this area. All persons living in this region are at risk for coccidioidomycosis, though the frequency and severity of disease are increased in specific persons, including those with impaired cellular immunity, the elderly, pregnant women and certain racial groups (e.g, Filipino, African). ${ }^{[25,26]}$

The second mode to use an immunomodulator is to treat invasive fungal disease. From a practical standpoint, the immunomodulator is used as adjunctive therapy in combination with an antifungal agent. Though several immunomodulatory strategies exist that target innate and antigen-specific immunity [Table 2], evidence of efficacy in well-designed clinical trials is sparse. ${ }^{[27]}$ Adjunctive immune-based therapy for CNS fungal diseases must also address specific challenges related to neuro-immunolozgy.

\section{Cryptococcus neoformans}

C. neoformans is unique among the pathogenic fungi in having a polysaccharide capsule that is a major virulence factor that allows the pathogen to evade phagocytosis. Acapsular variants of C. neoformans have attenuated virulence. The $C$. neoformans capsule 
also interferes with dendritic cell (DC) activation and maturation, a mechanism by which the fungus may suppress an effective T-cell response. ${ }^{[28]}$ The capsule is composed primarily of glucuronoxylomannan (GXM); GXM has an alpha-1,3 linked mannose backbone that is O-acetylated and substituted with single side chains of xylose and glucouronic acid. The degree of acetylation and xylose substitution can vary, producing four serotypes. Serial isolates of C. neoformans from chronically infected patients show changes in virulence, karyotype and capsular polysaccharide structure, suggesting that structural changes occur during chronic infection. ${ }^{[29]}$ "Phenotypic switching" (high frequency reversible changes in colony morphology) has been described in several strains of $C$. neoformans. For example, phenotypic switching in C. neoformans SB4 is associated with changes in colony morphology that included: 1) smooth, 2) wrinkled and 3) serrated. ${ }^{[30]}$ The wrinkled phenotype was the most virulent in experimental infection. Infection of rats with serrated C. neoformans produced the most intense inflammatory responses characterized by granuloma formation and necrosis. Wrinkled C. neoformans produced a minimal inflammatory response. Thus, phenotypic switching affects $\mathrm{C}$. neoformans virulence and the host inflammatory response, which may confer an advantage in establishing chronic infection and evading host defense.

Antibodies directed against capsular epitopes confer protection in murine cryptococcal infection. ${ }^{[31-35]}$ Radioimmunotherapy, in which antifungal antibodies are conjugated to radioisotopes are being evaluated in animal studies. ${ }^{[36,37]}$ Murine IgG1 (Mab 18B7) was well-tolerated in a Phase I dose-escalating trial in patients with cryptococcal meningitis. ${ }^{[38]}$ Additional Phase II and III studies will be required to demonstrate if adjunctive therapy with anti-cryptococcal antibody confers additional benefit over standard antifungal therapy alone.

\section{Interferon- $\gamma$}

Exposure to various pathogens can stimulate at least two patterns of cytokine production by CD4+ T-cells. Th1 cells are defined by production of interferon (IFN)$\gamma$, lymphotoxin and IL-2 and Th2 cells by production of IL-4, IL-5, IL-9, IL-10 and IL-13. Interferon- $\gamma$ is produced by lymphocytes (CD4+, CD8+, NK cells) as well as macrophages and perhaps neutrophils. ${ }^{[39]}$ It is induced by a number of signals, including IL-12 and IL-18 ${ }^{[40,41]}$ and in turn induces hundreds of genes, including its own inducers. ${ }^{[42,43]}$

Though several cytokines, including IL-12, IL-15 and TNF- $\alpha$ may also hold promise as adjunctive therapeutics, we will focus our discussion on IFN- $\gamma$ because the database on rIFN- $\gamma$ is the most developed. Several laboratories have shown that IFN- $\gamma$ augments the antifungal activity of effector cells (macrophages and neutrophils) ex-vivo against a variety of pathogens, including Candida albicans, Histoplasma capsulatum, Coccidiolides immitis, Cryptococcus neoformans and Aspergillus species. ${ }^{[27,44]}$ Data in mouse models using cytokine depletion, gene knockout mice and administration of exogenous cytokines have been instrumental in establishing the conceptual basis for immunotherapy in invasive mycoses and in paving the way to early clinical trials.

In murine cryptococcal infection, administration of IL-12, a potent inducer of the Th-1 type phenotype, resulted in $\sim 10$-fold decreases in the organism burden in the central nervous system. ${ }^{[45]}$ In addition, the combination of fluconazole plus IL-12 significantly decreased the organism burden compared with either agent alone. ${ }^{[45]}$ Lutz et al. ${ }^{[46]}$ evaluated combination IFN- $\gamma$ plus amphotericin B in murine cryptococcal infection. Interferon $\gamma$ alone was modestly effective but significantly potentiated amphotericin B in reducing infection in the brain. The efficacy was seen after both lethal and non-lethal challenges. In non-lethal infection, only the combination amphotericin B plus IFN- $\gamma$ resulted in sterilization of the central nervous system. Potentiation of fluconazole was less impressive. Ex-vivo amphotericin B augmented IFN- $\gamma$ induced killing of C. neoformans by mouse peritoneal macrophages. ${ }^{[47]}$ This enhanced killing was associated with IFN- $\gamma$-mediated augmentation of IL-1, TNF- $\alpha$ and nitric oxide production by peritoneal macrophages

These and other studies led to a study of adjunctive IFN- $\gamma$ in cryptococcal meningitis. Pappas et al. ${ }^{[48]}$ conducted a Phase II, double-blind, placebo-controlled study to evaluate the safety and antifungal activity of adjuvant recombinant IFN- $\gamma$ in AIDS-associated acute cryptococcal meningitis. Patients received 100 or 200 micrograms of rIFN- $\gamma$ or placebo, thrice weekly for 10 weeks, plus standard therapy with intravenous amphotericin B, with or without flucytosine, followed by therapy with fluconazole. End points included conversion of cerebrospinal fluid fungal cultures from positive to negative at two weeks, resolution of symptoms and survival. Among 75 patients, two-week CSF sterilization occurred in 13\% of placebo recipients, $36 \%$ of rIFN- $\gamma$ (100 micrograms) recipients and $32 \%$ of rIFN- $\gamma$ (200 micrograms) recipients. There was a trend toward improved combined mycologic and clinical success in rIFN- $\gamma$ recipients ( $26 \%$ vs. $8 \%$; $P=0.078$ ) and the drug was well tolerated.

AIDS-asssociated cryptococcal meningitis responds to standard antifungal therapy in approximately $70 \%$ of patients and 10-week survival following diagnosis is expected to be $90 \%{ }^{[49]}$ At this point, it is premature to use adjunctive cytokine therapy as routine care for cryptococcal meningitis. A Phase III trial with efficacy as the primary endpoint is required to demonstrate 
the benefits versus risk of $\mathrm{IIFN}-\gamma$. It is reasonable to consider rIFN- $\gamma$ in the setting of CNS disease refractory to standard antifungal therapy where options are very limited, though we emphasize that data in this setting are at the case report level. ${ }^{[50]}$

\section{Antiretroviral therapy in patients with HIV infection}

Without question, the most successful immune-based strategy to prevent cryptococcal disease in patients with HIV infection is the development of highly active antiretroviral therapy (HAART). In a large proportion of HIV-positive patients, HAART decreases the HIV viral load, enabling reconstitution of cellular immunity. McNeil et $a^{\left[{ }^{[7]}\right.}$ evaluated trends in mortality related to fungal diseases in the Unites States between 1980 and 1997. The number of cases of HIV-associated cryptococcal-disease-related fatalities increased in the mid and late 1980s, remained stable through the early and mid-1990s and then significantly decreased. The largest percentage decrease in C. neoformans-related mortality occurred in 1996-1997, coincident with the widespread use of HAART. Improved antifungal therapy and prophylaxis may have also influenced the reduction in cryptococcal disease-related mortality. Surveillance studies of HIV-associated cryptococcosis in the United States ${ }^{[51,52]}$ and France ${ }^{[53]}$ showed a reduction in cryptococcal disease associated with HAART, though, in some areas the decrease in the incidence of cryptococcosis predated the availability of HIV protease inhibitors. ${ }^{[51]}$

Immune reconstitution inflammatory syndrome (IRIS), results from an exuberant inflammatory response towards previously diagnosed or incubating pathogens (e.g, mycobacterial and cytomegalovirus disease). ${ }^{[54]}$ Immune reconstitution inflammatory syndrome is welldescribed in AIDS-associated cryptococcal meningitis following initiation of effective antiretroviral therapy and manifests with meningismus and elevated CSF opening pressures, protein levels and white blood cell counts. ${ }^{[55,56]}$ Repeat CSF cultures are required to distinguish IRIS from persistent or recrudescent cryptococcal disease. Immune reconstitution inflammatory syndrome does not represent treatment failure.

Studies have reported that in HIV-positive patients with prior cryptococcal meningitis who have an immunologic response to HAART, discontinuation of secondary antifungal prophylaxis is safe if patients are closely monitored for recrudescence of disease..$^{[57,58]}$ Our own practice is to continue secondary prophylaxis with fluconazole in these patients.

\section{Coccidiodes immitis}

The dimorphic fungi exist in the yeast form at body temperature and in the filamentous form at lower temperatures. C. immitis is endemic in southwestern
United States. The tissue form is the spherule. Arthroconidia are inhaled from the environment where they convert into spherules. Spherules enlarge (20 to $100 \mathrm{um}$ ) and segment internally into hundreds of endospores. Mature endospores rupture through the spherule where they can extend the local infection or disseminate. The spherule prevents access of neutrophils to maturing endospores and following rupture, endospores are themselves covered by a matrix from the inner spherule wall which may also aid in evading phagoctyosis. ${ }^{[59]}$ The potential for C. immitis to widely disseminate has prompted the search for extracellular fungal proteinase ${ }^{[60,61]}$ that may be targets for inhibitors or vaccines.

In mouse models, IFN- $\gamma$ plays a pivotal role in resistance to $\mathrm{C}$. immitis, whereas IL-4 down-regulates protective immunity against $\mathrm{C}$. immitis. ${ }^{[62]}$ Adjunctive therapy of refractory coccidioidomycosis with IFN- $\gamma$ in patients is anecdotal and cannot be routinely advised. ${ }^{[63]}$

Substantial effort has been devoted to developing a vaccine for coccidioidomycosis. In the 1980s, a randomized placebo-controlled study involving 2,867 subjects from endemic regions showed no benefit of the formalin-killed spherule vaccine in preventing coccidioidomycosis. ${ }^{[64]}$ Additional candidate vaccines for coccidioidomycosis are being developed, with efforts focused on identifying immunodominant Coccidioides antigens to be used in subunit vaccines (http:www. valleyfever.com/). Studies in multiple laboratories have shown that antigen 2/proline-rich antigen (Ag2/PRA) as both protein and DNA vaccines provide significant protection in experimental coccidioidomycosis. ${ }^{[65-69]}$ The completed and genomic sequence of $\mathrm{C}$. immitis may facilitate identifying new candidates antigens for vaccine development.

\section{Conclusions}

CNS fungal diseases are important causes of morbidity and mortality, particularly in the severely immunocompromized. Novel immune-based therapies are required both to prevent fungal diseases and as adjunctive therapy. Our review focused on cryptococcosis and coccidioidomycosis because of the propensity of these diseases to involve the CNS. Several immune augmentation strategies exist [Table 2]. Several challenges exist regarding bringing promising immune-based therapies developed in the lab to clinical trials (reviewed in). ${ }^{[27]}$ So far, clinical trials on CNS fungal diseases have involved Phase I and II trials in AIDS-associated cryptococcal meningitis. Such studies address safety and are not powered to evaluate efficacy. The widespread use of HAART in HIV-infected patients has dramatically decreased the incidence of cryptococcal meningitis, such that large pivotal clinical trials of cryptococcal meningitis may no longer be 
feasible in the United States because of inadequate patient numbers; collaboration with international study sites will likely be required. Several candidate vaccines against coccidioidomycosis are at pre-clinical stages of development.

\section{References}

1. Bow EJ, Loewen R, Cheang MS, Shore TB, Rubinger M, Schacter B. Cytotoxic therapy-induced D-xylose malabsorption and invasive infection during remission-induction therapy for acute myeloid leukemia in adults. J Clin Oncol 1997;15:2254-61.

2. Nussbaum GR, Casadevall YA, Scharff MD. Immunoglobulin G3 blocking antibodies to the fungal pathogen Cryptococcus neoformans. J Exp Med 1996;183:1905-9.

3. Kozel TR. Opsonization and phagocytosis of Cryptococcus neoformans. Arch Med Res 1993;24:211-8.

4. Griffin FM Jr. Roles of macrophage Fe and C3b receptors in phagocytosis of immunologically coated Cryptococcus neoformans. Proc Natl Acad Sci USA 1981;78:3853-7.

5. Monari CA, Casadevall D, Pietrella F, Bistoni, Vechiarelli A. Neutrophils from patients with advanced human immunodeficiency virus infection have impaired complement receptor function and preserved Fegamma receptor function. J Infect Dis 1999;180:1542-9.

6. Lendvai N, Casadevall A. Monoclonal antibody-mediated toxicity in Cryptococcus neoformans infection: Mechanism and relationship to antibody isotype. J Infect Dis 1999;180:791-801.

7. MeNeil MM, Nash SL, Hajjjeh RA, Phelan MA, Conn LA, Plikaytis BD, et al. Trends in mortality due to invasive mycotic diseases in the United States, 1980-1997. Clin Infect Dis 2001;33:641-7.

8. Denning DW. The aspergillus fumigatus genome database. The Institute for Genomic Research (TIGR). Available from: http://www.tigr.org/tdb/ e2k1/afu1/intro.shtml. 2003.

9. Patterson TF, Kirkpatrick WR, White M, Hiemenz JW, Wingard JR, Dupont B, et al. Invasive aspergillosis. Disease spectrum, treatment practices and outcomes. I3 Aspergillus Study Group. Medicine (Baltimore) 2000;79:250-60.

10. Denning DW. Therapeutic outcome in invasive aspergillosis. Clin Infect Dis 1996;23:608-15.

11. Yuen KY, Woo PC, Ip MS, Liang RH, Chiu EK, Siau H, et al, Stagespecific manifestation of mold infections in bone marrow transplant recipients: Risk factors and clinical significance of positive concentrated smears. Clin Infect Dis 1997;25:37-42.

12. Baddley JW, Stroud TP, Salzman D, Pappas PG. Invasive mold infections in allogeneic bone marrow transplant recipients. Clin Infect Dis 2001;32:1319-24.

13. Grow WB, Moreb JS, Roque D, Manion K, Leather H, Reddy V, et al. Late onset of invasive aspergillus infection in bone marrow transplant patients at a university hospital. Bone Marrow Transplant 2002;29:15-9.

14. Marr KA, Carter RA, Boeckh M, Martin P, Corey L. Invasive aspergillosis in allogeneic stem cell transplant recipients: Changes in epidemiology and risk factors. Blood 2002;100:4358-66.

15. Jantunen E, Ruutu P, Niskanen L, Volin L, Parkkali T, Koukila-Kahkola $\mathrm{P}$, et al. Incidence and risk factors for invasive fungal infections in allogeneic BMT recipients. Bone Marrow Transplant 1997;19:801-8.

16. Marr KA, Carter RA, Crippa F, Wald A, Corey L. Epidemiology and outcome of mould infections in hematopoietic stem cell transplant recipients. Clin Infect Dis 2002;34:909-17.

17. Dewsnup DH, Galgiani JN, Graybill JR, Diaz M, Rendon A, Cloud GA, et al. Is it ever safe to stop azole therapy for Coccidioides immitis meningitis? Ann Intern Med 1996;124:305-10.

18. Romani L. Immunity to fungal infections. Nat Rev Immunol 2004;4:123.

19. Stevens DA. Vaccinate against aspergillosis! A call to arms of the immune system. Clin Infect Dis 2004;38:1131-6.

20. Cox RA, Magee DM. Coccidioidomycosis: Host response and vaccine development. Clin Microbiol Rev 2004;17:804-39.
21. Wuthrich M, Filutowicz HI, Warner T, Deepe GS Jr, Klein BS. Vaccine immunity to pathogenic fungi overcomes the requirement for CD4 help in exogenous antigen presentation to CD8 + T cells: Implications for vaccine development in immune-deficient hosts. J Exp Med 2003;197:140516 .

22. Denning DW, Stevens DA. Antifungal and surgical treatment of invasive aspergillosis: Review of 2,121 published cases. Rev Infect Dis 1990;12:1147-201.

23. Schwartz SM, Ruhnke P, Ribaud L, Corey T, Driscoll OA, Cornely, et al. Improved outcome in central nervous system aspergillosis, using voriconazole treatment. Blood 2005;106:2641-5.

24. van der Veen RC, Dietlin TA, Hofman FM, Pen L, Segal BH, et al. Superoxide prevents nitric oxide-mediated suppression of helper $\mathrm{T}$ lymphocytes: Decreased autoimmune encephalomyelitis in nicotinamide adenine dinucleotide phosphate oxidase knockout mice. J Immunol 2000;164:5177-83.

25. Deresinski SC, Stevens DA. Coccidioidomycosis in compromised hosts. Experience at Stanford University Hospital. Medicine (Baltimore) 1975;54:377-95.

26. Galgiani JN, Ampel NM, Catanzaro A, Johnson RH, Stevens DA, Williams PL. Practice guideline for the treatment of eoccidioidomycosis. Infectious Diseases Society of America. Clin Infect Dis 2000;30:65861 .

27. Segal BH, Kwon-Chung J, Walsh TJ, Klein BS, Battiwalla M, Almyroudis NG, et al, Immunotherapy for fungal infections. Clin Infect Dis 2006;42:507-15.

28. Vechiarelli AD, Pietrella P, Lupo F, Bistoni DC, McFadden, Casadevall A. The polysaccharide capsule of Cryptococcus neoformans interferes with human dendritic cell maturation and activation. J Leukoc Biol 2003;74:370-8.

29. Fries BC, Goldman DL, Cherniak R, Ju R, Casadevall A. Phenotypic switching in Cryptococcus neoformans results in changes in cellular morphology and glucuronoxylomannan structure. Infect Immun 1999;67:6076-83.

30. Goldman DL, Fries BC, Franzot SP, Montella L, Casadevall A. Phenotypic switching in the human pathogenic fungus Cryptococcus neoformans is associated with changes in virulence and pulmonary inflammatory response in rodents. Proc Natl Acad Sci USA 1998;95:14967-72.

31. Casadevall AW, Cleare M, Feldmesser A, Glatman-Freedman DL, Goldman TR, Kozel, et al. Characterization of a murine monoclonal antibody to Cryptococcus neoformans polysaccharide that is a candidate for human therapeutic studies. Antimicrob Agents Chemother 1998;42:1437-46.

32. Dromer F, Charreire J, Contrepois A, Carbon C, Yeni P. Protection of mice against experimental cryptococcosis by anti-Cryptococcus neoformans monoclonal antibody. Infect Immun 1987;55:749-52.

33. Sanford JE, Lupan DM, Schlageter AM, Kozel TR. Passive immunization against Cryptococcus neoformans with an isotype-switch family of monoclonal antibodies reactive with cryptococeal polysaccharide. Infect Immun 1990;58:1919-23.

34. Mukherjee J, Scharff MD, Casadevall A. Protective murine monoclonal antibodies to Cryptococcus neoformans. Infect Immun 1992;60:453441.

35. Fleuridor R, Zhong Z, Pirofski L. A human IgM monoclonal antibody prolongs survival of mice with lethal cryptococcosis. J Infect Dis 1998;178:1213-6.

36. Dadachova E, Howell RW, Bryan RA, Frenkel A, Nosanchuk JD, Casadevall A. Susceptibility of the human pathogenic fungi Cryptococcus neoformans and $\mathrm{H}$ istoplasma capsulatum to gamma-radiation versus radioimmunotherapy with alpha- and beta-emitting radioisotopes. J Nucl Med 2004;45:313-20.

37. Dadachova E, Bryan RA, Frenkel A, Zhang T, Apostolidis C, Nosanchuk JS, et al. Evaluation of acute hematologic and long-term pulmonary toxicities of radioimmunotherapy of Cryptococcus neoformans infection in murine models. Antimicrob Agents Chemother 2004;48:1004-6.

38. Larsen RA, Pappas PG, Perfect J, Aberg JA, Casadevall A, Cloud GA, et al. Phase I evaluation of the safety and pharmacokinetics of murine-derived anticryptococcal antibody $18 \mathrm{~B} 7$ in subjects with treated cryptococeal meningitis. Antimicrob Agents Chemother 2005;49:9528. 
39. Wang J, Wakeham J, Harkness R, Xing Z. Macrophages are a significant source of type 1 cytokines during mycobacterial infection. J Clin Invest 1999;103:1023-9.

40. Mountford AP, Coulson PS, Cheever AW, Sher A, Wilson RA, Wynn TA Interleukin-12 can directly induce T-helper 1 responses in interferongamma (IFN-gamma) receptor-deficient mice, but requires IFNgamma signalling to downregulate T-helper 2 responses. Immunology 1999;97:588-94.

41. Tomura M, Maruo S, Mu J, Zhou XY, Ahn HJ, Hamaoka T, et al. Differential capacities of CD4+, CD8+ and CD4-CD8- T cell subsets to express IL-18 receptor and produce IFN-gamma in response to IL-18. J Immunol 1998;160:3759-65.

42. Boehm U, T Klamp, Groot M, Howard JC. Cellular responses to interferon-gamma. Annu Rev Immunol 1997;15:749-95.

43. Pien GC, Satoskar AR, Takeda K, Akira S, Biron CA. Cutting edge: Selective IL-18 requirements for induction of compartmental IFN-gamma responses during viral infection. J Immunol 2000;165:4787-91.

44. Stevens DA. Combination immunotherapy and antifungal chemotherapy. Clin Infect Dis 1998;26:1266-9.

45. Clemons KV, Brummer E, Stevens DA. Cytokine treatment of central nervous system infection: Efficacy of interleukin-12 alone and synergy with conventional antifungal therapy in experimental cryptococcosis. Antimicrob Agents Chemother 1994;38:460-4.

46. Lutz JE, Clemons KV, Stevens DA. Enhancement of antifungal chemotherapy by interferon-gamma in experimental systemic cryptococcosis. J Antimicrob Chemother 2000;46:437-42.

47. Tohyama M, Kawakami K, Saito A. Anticryptococeal effect of amphotericin B is mediated through macrophage production of nitric oxide. Antimicrob Agents Chemother 1996;40:1919-23.

48. Pappas PG, Bustamante B, Ticona E, Hamill RJ, Johnson PC, Reboli A, et al. Recombinant interferon- gamma $1 \mathrm{~b}$ as adjunctive therapy for AIDSrelated acute cryptococeal meningitis. J Infect Dis 2004;189:2185-91.

49. van der Horst CM, Saag MS, Cloud GA, Hamill RJ, Graybill JR, Sobel JD, et al. Treatment of eryptococeal meningitis associated with the acquired immunodeficiency syndrome. National Institute of Allergy and Infectious Diseases Mycoses Study Group and AIDS Clinical Trials Group. N Engl J Med 1997;337:15-21.

50. Netea MG, Brouwer AE, Hoogendoorn EH, van der Meer JW, Koolen M, Verweij PE, et al. Two patients with cryptococcal meningitis and idiopathic CD4 lymphopenia: Defective cytokine production and reversal by recombinant interferon- gamma therapy. Clin Infect Dis 2004;39: e83-7.

51. Mirza SA, Phelan M, Rimland D, Graviss E, Hamill R, Brandt ME, et al. The changing epidemiology of cryptococeosis: An update from populationbased active surveillance in 2 large metropolitan areas, 1992-2000. Clin Infect Dis 2003;36:789-94.

52. Friedman GD, Jeffrey Fessel W, Udaltsova NV, Hurley LB. Cryptococcosis: The 1981-2000 epidemic. Mycoses 2005;48:122-5.

53. Dromer F, Mathoulin-Pelissier S, Fontanet A, Ronin O, Dupont B, Lortholary O, Epidemiology of HIV-associated cryptococeosis in France (1985-2001):comparison of the pre- and post-HAART eras. AIDS 2004:18:555-62.

54. Shelburne SA, Visnegarwala F, Darcourt J, Graviss EA, Giordano T, White AC Jr, et al. Incidence and risk factors for immune reconstitution inflammatory syndrome during highly active antiretroviral therapy. AIDS 2005;19:399-406.

55. Lortholary O, Fontanet A, Memain N, Martin A, Sitbon K, Dromer F. Incidence and risk factors of immune reconstitution inflammatory syndrome complicating HIV-associated cryptococcosis in France. AIDS $2005 ; 19: 1043-9$.

56. Shelburne SA $3^{\text {rd }}$, Darcourt J, White AC Jr, Greenberg SB, Hamill RJ, Atmar RL, et al. The role of immune reconstitution inflammatory syndrome in AIDS-related Cryptococcus neoformans disease in the era of highly active antiretroviral therapy. Clin Infect Dis 2005;40:1049-52.

57. Vibhagool A, Sungkanuparph S, Mootsikapun P, Chetchotisakd P, Tansuphaswaswadikul S, Bowonwatanuwong C, et al. Discontinuation of secondary prophylaxis for cryptococcal meningitis in human immunodeficiency virus-infected patients treated with highly active antiretroviral therapy: A prospective, multicenter, randomized study Clin Infect Dis 2003;36:1329-31.

58. Mussini C, Pezzotti P, Miró JM, Martinez E, de Quiros JC, Cinque P, et al. Discontinuation of maintenance therapy for cryptococcal meningitis in patients with AIDS treated with highly active antiretroviral therapy: An international observational study. Clin Infect Dis 2004;38:565-71.

59. Frey CL, Drutz DJ. Influence of fungal surface components on the interaction of Coccidioides immitis with polymorphonuclear neutrophils. $J$ Infect Dis 1986;153:933-43.

60. Cole GT, Zhu SW, Hsu LL, Kruse D, Seshan KR, Wang F. Isolation and expression of a gene which encodes a wall-associated proteinase of Coccidioides immitis. Infect Immun 1992;60:416-27.

61. Johnson SM, Kerekes KM, Zimmermann CR, Williams RH, Pappagianis D. Identification and cloning of an aspartyl proteinase from Coccidi oi des immitis. Gene 2000;241:213-22.

62. Magee DM, Cox RA. Roles of gamma interferon and interleukin-4 in genetically determined resistance to Cocci di oi des i mmi tis. Infect Immun 1995;63:3514-9

63. Kuberski TT, Servi RJ, Rubin PJ. Successful treatment of a critically ill patient with disseminated coccidioidomycosis, using adjunctive interferongamma. Clin Infect Dis 2004;38:910-2.

64. Pappagianis D. Evaluation of the protective efficacy of the killed Coceidioides immitis spherule vaccine in humans. The Valley Fever Vaccine Study Group. Am Rev Respir Dis 1993;148:656-60.

65. Jiang C, Magee DM, Ivey FD, Cox RA. Role of signal sequence in vaccine-induced protection against experimental coccidioidomycosis Infect Immun 2002;70:3539-45.

66. Peng T, Shubitz L, Simons J, Perrill R, Orsborn KI, Galgiani JN. Localization within a proline-rich antigen (Ag2/PRA) of protective antigenicity against infection with Coccidi oides immitis in mice. Infect Immun 2002;70:3330-5.

67. Silva AJ, Benitez JA. Th1-type immune response to a Coccidioides immitis antigen delivered by an attenuated strain of the non-invasive enteropathogen Vibrio cholerae. FEMS Immunol Med Microbiol $2005 ; 43: 393-8$

68. Silva AJ, Mohan A, Benitez JA. Cholera vaccine candidate 638: Intranasal immunogenicity and expression of a foreign antigen from the pulmonary pathogen Coccidi oi des immitis. Vaccine 2003;21:4715-21.

69. Abuodeh RO, Shubitz LF, Siegel E, Snyder S, Peng T, Orsborn KI, et al. Resistance to Coccidioides immitis in mice after immunization with recombinant protein or a DNA vaceine of a proline-rich antigen. Infect Immun 1999;67:2935-40.

Accepted on 09-05-2007

Source of Support: Nil, Conflict of Interest: None declared. 